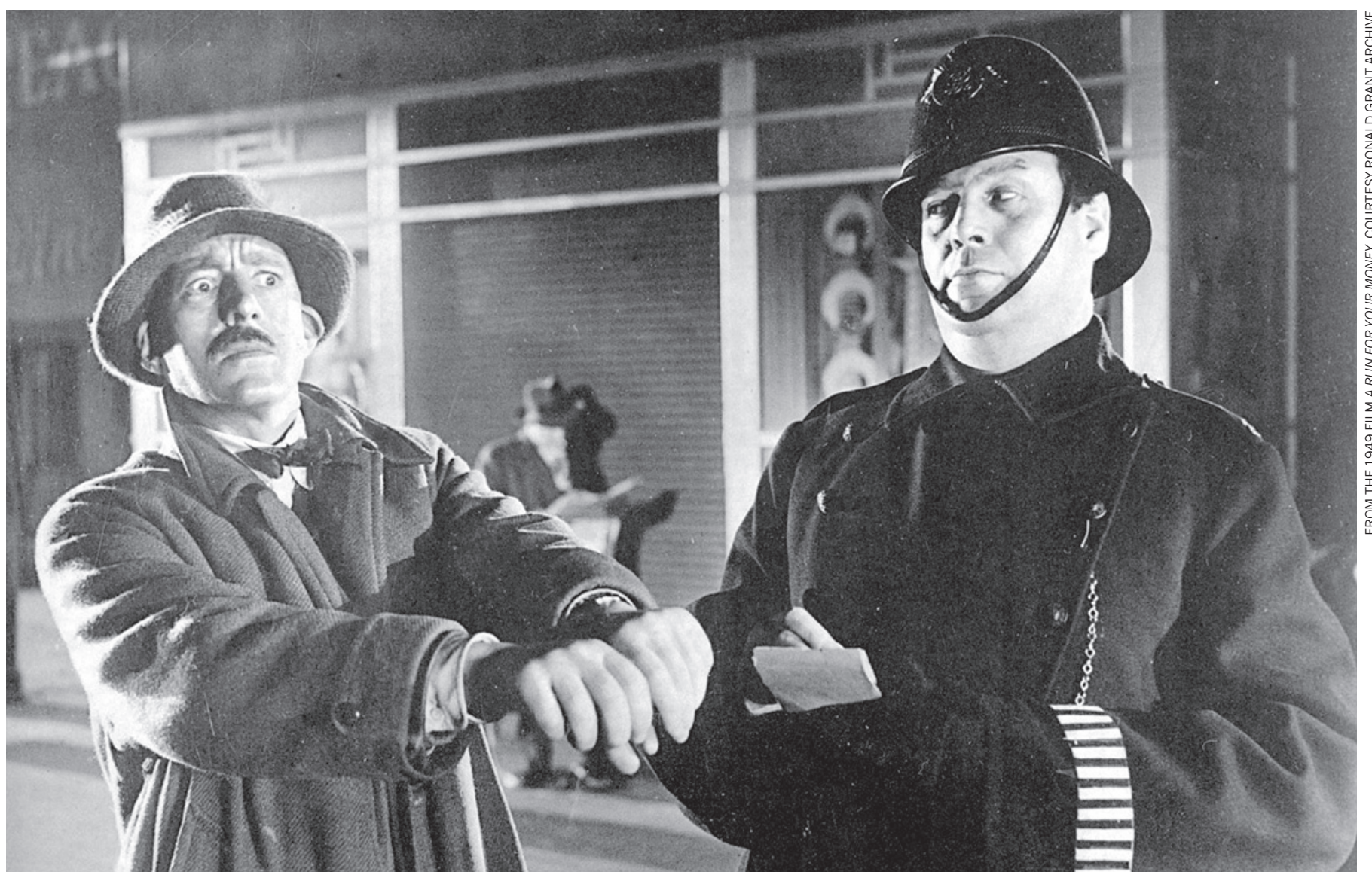

Better understanding of decision-making processes in the brain might predict which perpetrators will offend again.

NEUROSCIENCE

\title{
My brain made me do it
}

\section{Adam Kepecs urges caution in considering the unconscious mind in the justice system.}

A

surprising view has been gathering momentum in neuroscience: most of our thoughts and actions are driven by unconscious brain processes that are hidden from conscious introspection. So if consciousness is rarely in the driver's seat, and if we cannot choose our genes or the childhood experiences whose interactions form our brains, then are we responsible for our actions?

In Incognito, accomplished neuroscientist David Eagleman - author of the best-selling short-story collection Sum (Canongate, 2010) - examines this gap between our conscious and unconscious selves. He offers a whirlwind of stories, from visual illusions and sleep-walking killers to ovulating strippers, all carefully chosen to drive home his main point that our brains "neurally preordain" us to make decisions. As is common in books aimed at a general readership, the intriguing and sometimes bizarre case studies create a tension between

journalistic musings and more detailed arguments. Although specialists may feel that the balance tilts toward the journalistic, Eagleman's expertise comes through.

Since Sigmund Freud's famous psychological framing of the unconscious in the late nineteenth century, modern neuro-

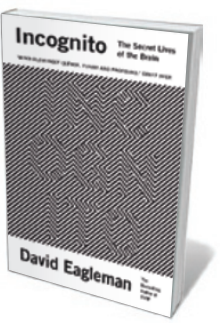

Incognito: The Secret Lives of the Brain

DAVID EAGLEMAN Pantheon/Canongate: 2011. 304 pp./272 pp $\$ 26.95 / £ 20$ science has shown that most processing in the brain is unconscious. We are unaware of routine processes and have little insight into our choices and preferences. For instance, men unknowingly prefer photographs of women with dilated pupils, presumably because male brains evolved algorithms to recognize pupil dilation as an indicator of sexual arousal. In another experiment, people's descriptions of the strategies they used to make simple economic decisions differed from the rules that they actually used, suggesting that their conscious explanations were formed post hoc and without access to their decision-making process. Through such examples, Eagleman demonstrates that unconscious processes can be clever, adaptive and even outperform the best computer algorithms.

If our brains can carry out such amazing feats without us knowing, why have consciousness at all? Eagleman answers this question with a metaphor. Consciousness, he says, is like the chief executive of a large company. He or she has little knowledge of the day-to-day operations, yet is indispensable for setting goals and arbitrating between conflicting departments. Similarly, $\rightarrow$ NATURE.COM See Nature's special issue on Science in Court:

go.nature.com/ezbpwk 
consciousness gets only the abridged, delayed and sometimes contradictory reports from neural subroutines. And, much like a chief executive trying to explain him- or herself to the board of directors, consciousness will "fabricate stories to explain the sometimes inexplicable dynamics of subsystems in the brain".

Having described the hidden life of our brain circuits, Eagleman moves to an original and provocative discussion of the legal consequences of the unconscious decider within us. Imagine two defendants on trial for murder: one has a large brain tumour next to an area associated with aggression, whereas the other one shows no obvious change in his brain. Most people would not hold the first defendant responsible for his actions. Eagleman argues that as we gain a better understanding of the biology of decision-making, we will be forced to conclude that all crime is caused by faulty brain circuits arising from genetic and environmental interactions over which the perpetrator has no control.

An improved understanding of how subtle changes in the brain generate deviant behaviour would therefore extend the insanity defence - 'my brain made me do it'. Eagleman suggests that a forward-looking legal system should consider biological information to predict how likely a person is to commit a crime again, and take this into account for sentencing. As most criminals commit offences because they are unable to inhibit their impulses, Eagleman proposes that rehabilitative "prefrontal workouts", aimed at improving self-control, should be a mainstay of the justice system. Crime would still land you in jail, but the focus would be on protecting society, not on punishment.

My feeling is that we need to be extremely cautious in advancing such a brain-centric legal system. A world in which judges are instructed to consider the genetics and neural make-up of defendants, as Eagleman advocates, evokes Phillip K. Dick's short story The Minority Report. If sentencing decisions consider the biological likelihood of recommitting a crime, it is easy to imagine the next step of considering preventive measures before a crime has been committed - a kind of 'Department of Precrime'.

Whether or not one agrees with Eagleman, discussions about these difficult issues at the intersection of neuroscience and society are essential and timely. He should be lauded for his clear exposition of the consequences of our emerging understanding of the brain. Incognito is a smart, captivating book that will give you a prefrontal workout.

Adam Kepecs is assistant professor of neuroscience at Cold Spring Harbor Laboratory, 1 Bungtown Road, Cold Spring Harbor, New York 11724, USA.

e-mail:kepecs@cshl.edu

\section{Books in brief}

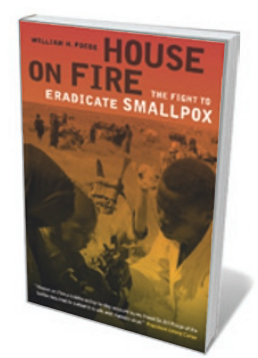

House on Fire: The Fight to Eradicate Smallpox

William H. Foege UNIVERSITY OF CALIFORNIA PRESS 240 pp.

$\$ 29.95$ (2011)

Adding to the series of California/Milbank Books on Health and the Public, this part-memoir, part-history by epidemiologist William Foege recounts his involvement in the global vaccination programmes that eradicated smallpox in the 1960s and 1970s. Foege, now a senior fellow at the Bill \& Melinda Gates Foundation in Seattle, Washington, reflects on the strategies that led to wide uptake of the vaccines across Africa and India and discusses their successes and vulnerabilities.

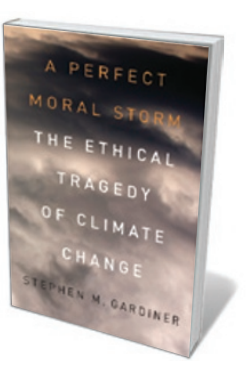

A Perfect Moral Storm: The Ethical Tragedy of Climate Change Stephen M. Gardiner OXFORD UNIVERSITY PRESS 512 pp. $£ 22.50$ (2011)

Inaction on climate change is more than a political or explanatory bungle - it is a moral failure, declares philosopher Stephen Gardiner. He identifies three reasons for this: the global imbalance of power, such that rich nations dominate poor ones; intergenerational factors, such that present generations dictate the world that future ones will inhabit; and our inability to make predictions using current scientific knowledge. A 'perfect storm' of these three factors creates an ethical headache, Gardiner contends.

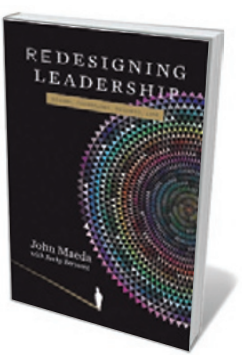

Redesigning Leadership: Design, Technology, Business, Life John Maeda with Becky Bermont MIT PRESS 104 pp. \$18 (2011) Celebrated designer and computer scientist John Maeda shares his thoughts on leadership in this concise volume. Interspersing his musings with philosophical tweets, he reflects on how he has sought out imaginative ways to run teams and organizations, from the Media Lab at the Massachusetts Institute of Technology in Cambridge to the Rhode Island School of Design in Providence. He describes how to make meetings run faster and be more fun, the team-building benefits of free food and how to harness conflicting opinions within a group of creatives.

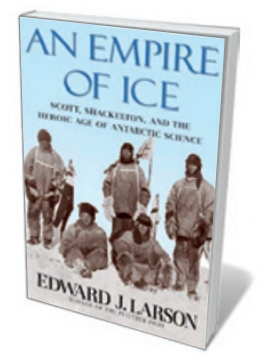

An Empire of Ice: Scott, Shackleton, and the Heroic Age of Antarctic Science

Edward J. Larson YALE UNIVERSITY PRESS 360 pp. £18.99 (2011)

Looking at the broader context of the race to be first to reach the South Pole in the early twentieth century, historian Edward Larson celebrates the centenary of these explorers' achievements. It was the greater scientific ambition of the British Antarctic expeditions, he argues, that caused Robert Scott and Ernest Shackleton to be slower than their more narrowly focused Norwegian rival, Roald Amundsen, who made it to the South Pole 35 days before Scott and his ill-fated team.

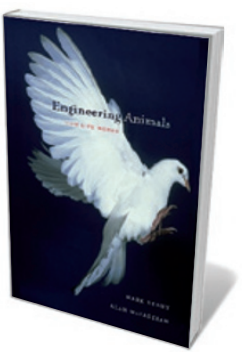

Engineering Animals: How Life Works

Mark Denny and Alan McFadzean BeLKNAP PRESS/HARVARD UNIVERSITY PRESS 400 pp. $\$ 35$ (2011)

From soaring albatrosses to croaking bullfrogs, different creatures exploit various aspects of engineering to help them fly, hunt or communicate. In a clear and well-illustrated account, former aerospace engineers Mark Denny and Alan McFadzean describe the principles of physics that underlie animals' sense of smell, their use of sonar, and how they flock, signal to each other and consume energy. 